\title{
Hospital physicians' work stressors in different medical specialities: a statistical group comparison
}

\author{
Grit Tanner $^{1 *}$, Eva Bamberg ${ }^{1}$, Agnessa Kozak², Maren Kersten ${ }^{3}$ and Albert Nienhaus ${ }^{2,3}$
}

\begin{abstract}
Background: Some studies on the occupational health of hospital physicians have found that working conditions have different effects on physician's well-being and health in different medical specialities. There has been no comparative study of the effects of various work stressors in different specialities. This study aims to close this gap.

Methods: German hospital physicians were asked about their working conditions and aspects of health. The short version of the Instrument for Stress-Related Job Analysis for Hospital Physicians was used to measure working conditions. Irritation and emotional exhaustion were used to assess health. Physicians were also asked for socio-demographic aspects, including their medical speciality.

Results: Data from 763 hospital physicians were included in the analyses. Significant differences between medical specialities were demonstrated for time pressure, uncertainty, frustration about how work needs to be done and social stressors with patients. Physicians in internal medicine showed consistently high levels of stressors. Time pressure, frustration about how work needs to be done, and emotional dissonance were found to be significantly related to both aspects of health.

Conclusions: The results showed that some medical specialities are more affected by specific stressors. It is therefore discussed how improvements can be implemented. Furthermore, it is illustrated which stressors are especially relevant for health. These relationships to health should be investigated in further research and in longitudinal designs to allow hints of causal relationships.
\end{abstract}

Keywords: Work stressors, Physicians' everyday work, Comparison of medical specialities, Emotional exhaustion, Irritation

\section{Background}

There have been several scientific studies on the working conditions of hospital physicians [1-7]. The considered aspects include job satisfaction [1], work-life balance [2], multitasking and work interruptions $[4,5]$. Thereby, relationships to health have often been examined.

How specific working conditions can affect employees' health is described in the extension of the transactional stress model in work and organisational psychology [8]. Stress is seen as a process that arises by assessing and then mastering the situation (either problem- or emotion-

\footnotetext{
* Correspondence: grit.tanner@uni-hamburg.de

${ }^{1}$ University of Hamburg, Work and Organisational Psychology, Von-Melle-Park 11, 20146 Hamburg, Germany

Full list of author information is available at the end of the article
}

focused). The starting points for this process are situationrelated stressors (e.g., time pressure), person-related risk factors (e.g., illness), as well as situation-related resources (e.g., social support) and person-related resources (e.g., self-efficacy). Stressors are characteristics that increase the probability of stress-outcomes. Resources are characteristics that can be used to master demands [8]. Situationrelated stressors and resources represent the work environment. Both influence the assessment and mastery of situations and - in unfavourable proportions - lead to stress-outcomes. Aside from the work environment, person-related factors influence this process and cause or prevent the stress-outcomes as well. On the other hand, stress-outcomes interact directly with the above mentioned starting points.

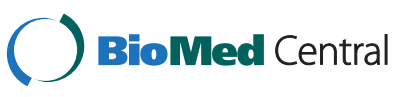

(C) 2015 Tanner et al.; licensee BioMed Central. This is an Open Access article distributed under the terms of the Creative Commons Attribution License (http://creativecommons.org/licenses/by/4.0), which permits unrestricted use, distribution, and reproduction in any medium, provided the original work is properly credited. The Creative Commons Public Domain Dedication waiver (http://creativecommons.org/publicdomain/zero/1.0/) applies to the data made available in this article unless otherwise stated. 
In accordance with the transactional stress model of work and organisational psychology, studies have investigated specific situation-related stressors and resources within hospital physicians' work, as well as relationships to other health aspects. Longitudinal studies have found long-term effects on health aspects - particularly for resources. Especially, autonomy was shown to be related to depressive symptoms in long-term $[9,10]$. Several cross-sectional studies have investigated whether situation-related stressors, health aspects and their relationships differ with respect to other factors such as medical speciality. For example, one study has examined differences between emergency physicians and other physicians [11]. The results show that, for emergency physicians, poor collaboration with colleagues is more closely related to intention to quit and burnout than for other physicians. On the other hand, the relationship between worry about making errors and burnout was about the same in the two samples [11]. For work engagement and burnout in assistant physicians, one study showed that there were differences between the medical specialities [12]. A further study has also shown that there are differences between the different medical specialities with respect to the working time of hospital physicians in Germany [13].

These results illustrate that stressors may have different effects in different medical specialities. But there has not been any comparison of different specialities across various stressors that cover almost the whole physicians' working day. The current study aimed to bridge this gap by examining various situation-related stressors during the daily work of hospital physicians. These are compared for different specialities, so that any improvements could be developed specifically for the specialities. Moreover, relationships between stressors and stress-outcomes are examined. The current study primarily focuses only on stressors, as including other factors would increase the complexity to an excessive degree.

\section{Methods}

This project was entitled Stress-Related Job Analysis for Hospital Physicians (StArK) and was carried out by the Institute for Statutory Accident Insurance and Prevention in the Health and Welfare Services, University of Hamburg and University Medical Center HamburgEppendorf, in order to examine hospital physicians' working conditions and their relationships to health.

\section{Sample}

Within the StArK project, hospital physicians throughout Germany were requested to evaluate their working conditions via questionnaire from February 2012 to December 2012. In addition, a link to the online survey was published in the newsletter of the official journal for
German physicians (Deutsches Ärzteblatt). Thus, hospital physicians could take part in the survey independently of their hospitals. To ensure that the results were reliable, only medical specialities with more than ten participants were included.

\section{Measures}

The short version of the "Instrument for Stress-Related Job Analysis for Hospital Physicians" (ISAK-K) [14] was used to measure specific stressors of hospital physicians' work. This instrument includes seven different stressors. On the one hand, task-related stressors, such as time pressure and uncertainty (e.g., from insufficient information) as well as frustration about how work needs to be done were investigated. On the other hand, interactionrelated stressors were considered, including problems in workflow due to physicians (supervisors and colleagues) and other professional groups (e.g., keeping to agreements, transmission of information), social stressors with patients and their families, and emotional dissonance (control of personal emotions). The stressors contain two to three items, which were rated on a 5-point Likert-scale.

Two aspects were selected to assess psychological health: Irritation [15] and emotional exhaustion [16]. Irritation describes work-related rumination after work. This includes additional effects on the state of mind (feeling of tension and irritability) [15]. Irritation represents a precursor to more serious psychological impairments. The eight items were answered on a 7-point Likert-scale, from 1 (does not apply at all) to 7 (applies nearly completely). Emotional exhaustion results in long-term from excessive efforts, both emotional and physical [17]. It is characterised by avolition and a feeling of weakness. One cause of emotional exhaustion may be that professional

Table 1 Sample characteristics

\begin{tabular}{lll}
\hline & $\begin{array}{l}\text { Total sample } \\
\mathbf{( N = 8 1 7 )}\end{array}$ & $\begin{array}{l}\text { Study sample } \\
(\mathbf{n}=\mathbf{7 6 3})\end{array}$ \\
Mean age & $\mathbf{4 1 . 0}$ (SD 9.8) & $\mathbf{4 0 . 7}$ (SD 9.8) \\
\hline Gender & & \\
Female & $44.2 \%$ & $43.0 \%$ \\
Male & $55.8 \%$ & $57.0 \%$ \\
Main medical specialities & & \\
Internal medicine & $21.8 \%$ & $23.3 \%$ \\
Surgery & $18.2 \%$ & $19.5 \%$ \\
Anaesthesia & $15.8 \%$ & $16.9 \%$ \\
Professional position & & \\
Assistant physician & $39.7 \%$ & $40.8 \%$ \\
Consulting physician & $18.9 \%$ & $18.3 \%$ \\
Senior physician & $32.7 \%$ & $32.5 \%$ \\
Chief physician & $8.7 \%$ & $8.4 \%$ \\
\hline
\end{tabular}


Table 2 One-way analyses of variance for the stressors by medical speciality

\begin{tabular}{|c|c|c|c|c|c|c|c|c|c|c|c|c|}
\hline & $\begin{array}{l}\text { Anaesthesia } \\
(n=129)\end{array}$ & $\begin{array}{l}\text { Surgery } \\
(n=149)\end{array}$ & $\begin{array}{l}\text { Obstetrics and } \\
\text { gynaecology } \\
(n=60)\end{array}$ & $\begin{array}{l}\text { Internal } \\
\text { medicine } \\
(n=178)\end{array}$ & $(n=52)$ & $(n=20)$ & $(n=44)$ & $(n=46)$ & $\begin{array}{l}\text { Psychiatry and } \\
\text { psychotherapy } \\
(n=50)\end{array}$ & $(n=23)$ & $(n=12)$ & $\mathrm{F}$ \\
\hline Time pressure & 3.59 & 3.49 & $3.13^{\mathrm{a}}$ & $3.76^{a, b, c}$ & $3.15^{b}$ & 3.85 & 3.74 & 3.45 & $3.14^{c}$ & 3.74 & 3.92 & $3.93^{* * *}$ \\
\hline Uncertainty ${ }^{1}$ & $3.32^{\mathrm{d}, \mathrm{e}}$ & $2.94^{f}$ & $2.53^{\mathrm{d}, \mathrm{ggh}}$ & $3.27^{9}$ & $2.68^{e, i}$ & 3.33 & $3.53^{\mathrm{f}, \mathrm{h}, \mathrm{i}}$ & 3.00 & 2.83 & 3.09 & 3.04 & $4.71^{* * *}$ \\
\hline $\begin{array}{l}\text { Frustration about how work } \\
\text { needs to be done }\end{array}$ & $2.78^{j}$ & $2.93^{k}$ & $2.80^{\prime}$ & $3.33^{\mathrm{j}, \mathrm{k}, \mathrm{l}}$ & 2.78 & 2.93 & 3.35 & 3.05 & 2.96 & 2.58 & 3.28 & $3.85^{* * *}$ \\
\hline $\begin{array}{l}\text { Problems in workflow due to } \\
\text { supervisors and colleagues }\end{array}$ & 2.45 & 2.29 & 2.43 & 2.47 & 2.09 & 2.38 & 2.19 & 2.47 & 2.28 & 2.52 & 2.58 & 1.47 \\
\hline $\begin{array}{l}\text { Problems in workflow due to } \\
\text { other professional groups }\end{array}$ & 2.45 & 2.45 & 2.65 & 2.71 & 2.30 & 2.55 & 2.65 & 2.67 & 2.44 & 2.72 & 2.63 & 1.84 \\
\hline $\begin{array}{l}\text { Social stressors with patients/ } \\
\text { families }\end{array}$ & $2.11^{m, n, o, p, q}$ & $2.54^{\mathrm{m}}$ & $2.19^{r, s, t}$ & $2.85^{n, r, u}$ & 2.45 & 2.45 & $3.01^{0, S, V}$ & $2.75^{p, w}$ & $2.88^{q, t, x}$ & $1.89^{\mathrm{u}, \mathrm{v}, \mathrm{w}, \mathrm{x}}$ & 2.67 & $9.33^{* * *}$ \\
\hline Emotional dissonance ${ }^{1}$ & 2.52 & 2.41 & 2.33 & 2.54 & 2.15 & 2.43 & 2.48 & 2.75 & 2.97 & 2.28 & 2.71 & 1.96 \\
\hline
\end{tabular}

$\mathrm{N}=763$. Post-hoc test: Bonferroni. ${ }^{1}$ Because of the heterogeneous variance, tested with the Welch-test and Post-hoc test: Dunnett-T3.

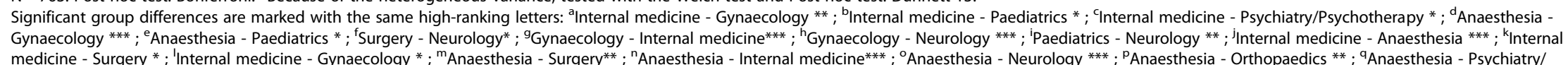

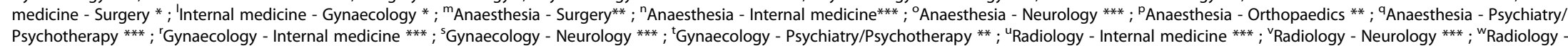
Orthopaedics * ; ${ }^{\mathrm{R}}$ Radiology - Psychiatry/Psychotherapy ***.

${ }^{*} \mathrm{p}<.05 ;{ }^{* *} \mathrm{p}<.01 ;{ }^{* * *} \mathrm{p}<.001$. 
effort is not adequately rewarded (e.g., by appreciation) [18]. Emotional exhaustion was measured with six items [16], which were answered on a 7-point Likert-scale, from 1 (never) to 7 (daily). Furthermore, on the basis of other studies control variables were selected. These studies demonstrated effects related to the medical speciality $[12,13]$, the professional position or age $[10,19]$ and gender [10].

\section{Statistical analyses}

The comparison of medical specialities was conducted with one-way analyses of variance (ANOVA). The Bonferroni procedure (post-hoc test) was used to identify the groups with significant differences. If variance heterogeneity was confirmed, the Welch test was applied to examine the differences, followed by the Dunnett-T3 procedure for the post-hoc tests. The Bonferroni correction was used to counteract the accumulation of $\alpha$-error [20]. Thus the significant ANOVA results presented here correspond to the corrected p-value.

Multiple hierarchical regression analyses were used to investigate the relationships between all stressors examined and each health aspect. In the first step, control variables were included, to ascertain whether, independently of these, there still is a relationship between the stressors and the health aspect. In the second step, all taskrelated stressors were included, followed by interactionrelated stressors in the third step.

\section{Results}

In sum, data were collected from 817 German hospital physicians. The response rate of the acquisition via hospitals was 30.6\% (705 hospital physicians). Additionally, with a response rate of $40.4 \%$ and a completion rate of $20.3 \%, 112$ hospital physicians participated in the open online-survey. After excluding groups smaller than ten participants (e.g., ENT physicians, occupational physicians, ophthalmologists, and pathologists), 763 physicians were included in the analyses - split into eleven different medical specialities. Socio-demographic characteristics of the samples are presented in Table 1. Both samples are comparable with German physician statistics [21,22].

\section{Comparison of specialities}

Various differences were found between the medical specialities with respect to the examined stressors (see Table 2; for a schematic overview see Figures 1, 2, 3, and 4). Time pressure and the frustration about how work needs to be done were rated higher by physicians in internal medicine than by those in obstetrics and gynaecology or in paediatrics (see Figures 1 and 2). Surgeons reported lower levels of frustration than physicians in internal medicine. Psychiatrists and psychotherapists reported lower levels of time pressure than physicians in internal medicine. Uncertainty was rated lower by physicians in obstetrics and gynaecology than by physicians in internal medicine, anaesthesia and neurology (see Figure 3). Moreover, physicians in paediatrics rated uncertainty lower than physicians in anaesthesia and neurology. Neurologists rated uncertainty higher than did surgeons. Several significant differences were found with respect to social stressors with patients and their families (see Figure 4). Physicians in radiology, anaesthesia, and in obstetrics and gynaecology rated social stressors significantly lower than did physicians in internal medicine, neurology, and in psychiatry and psychotherapy. Physicians in orthopaedics and rehabilitation rated social stressors higher than did physicians in radiology and anaesthesia. Surgeons gave also higher rates for social stressors than did physicians in anaesthesia. On the other hand, for the stressors problems in workflow due to physicians and other professional

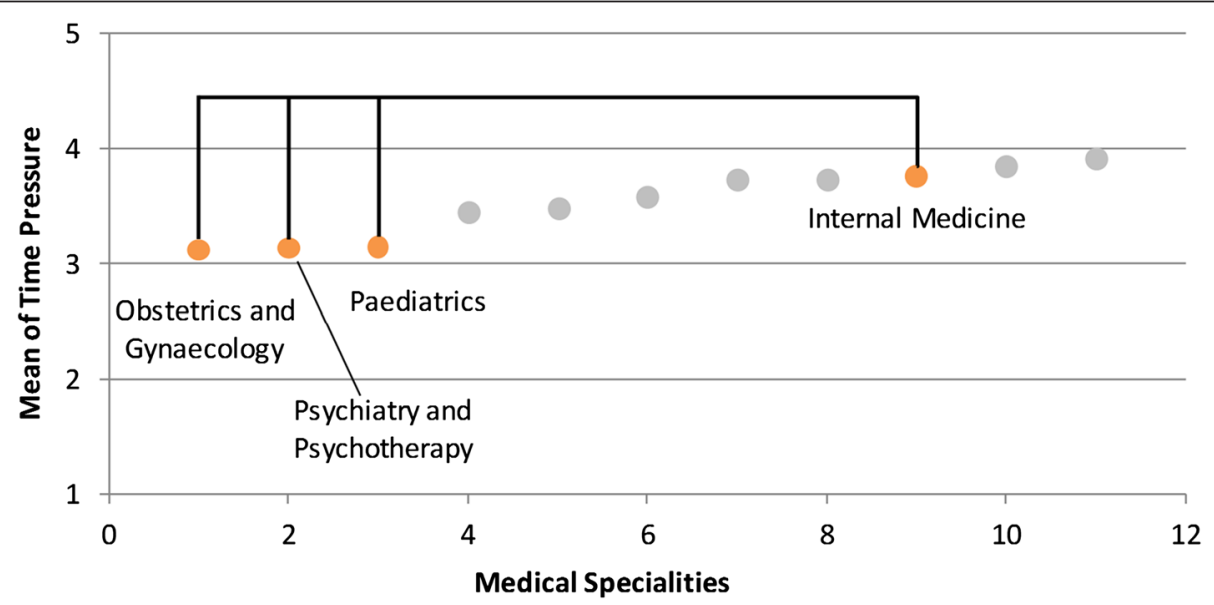

Figure 1 Differences between internal medicine and other specialities in time pressure. This is only a schematic figure of the differences found in time pressure. For detailed results use Table 2. 


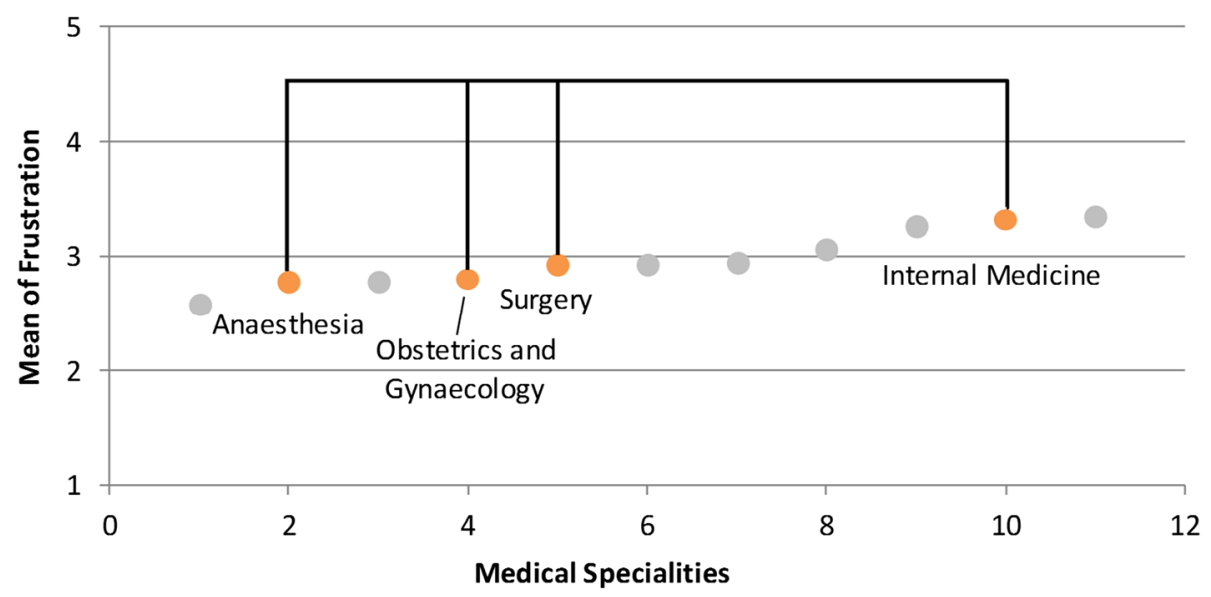

Figure 2 Differences between internal medicine and other specialities in frustration. This is only a schematic figure of the differences found in frustration about how work needs to be done. For detailed results use Table 2.

groups and emotional dissonance, there were no significant differences between the ratings in the medical specialities.

\section{Relationships between Stressors and Health}

As can be seen in Table 3, all stressors - as well as the control variables age, gender, and professional position showed significant correlations with the health aspects irritation and emotional exhaustion. There was no significant correlation between the medical speciality and the two health aspects. In the multiple regression analyses with control for age, gender, professional position and medical speciality, results were different. Of the task-related stressors, time pressure and frustration about how work needs to be done showed significant relationships to both irritation and emotional exhaustion. Of the interaction-related stressors, only emotional dissonance showed a significant relationship to both stress-outcomes. In addition, problems in workflow due to other professional groups were significantly related to emotional exhaustion. Moreover, beyond task-related stressors, interactionrelated stressors explained 5 to $7 \%$ of additional variance in the stress-outcomes.

\section{Discussion}

Especially physicians in internal medicine rated stressors more highly than do physicians in other specialities. Assuming that specific stressors (e.g., stressors with patients, lack of information) are negatively related to work engagement $[23,24]$, these results support the findings of a study with Dutch assistant physicians [12]. In this study, physicians in internal medicine showed less work engagement than colleagues in other specialities, combined with high emotional exhaustion [12]. However, the latter finding was not confirmed in the current study, as no relationship between medical speciality and emotional exhaustion was found. The differences with respect to the social stressors

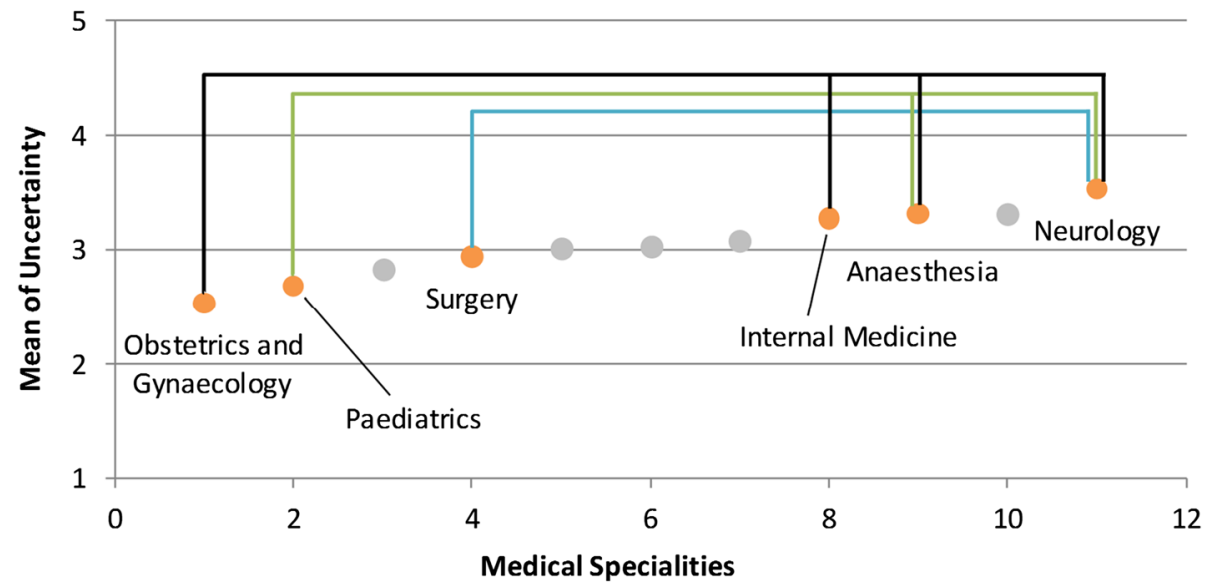

Figure 3 Differences between gynaecology, paediatrics, or surgery and other specialities in uncertainty. This is only a schematic figure of the differences found in uncertainty. For detailed results use Table 2. 


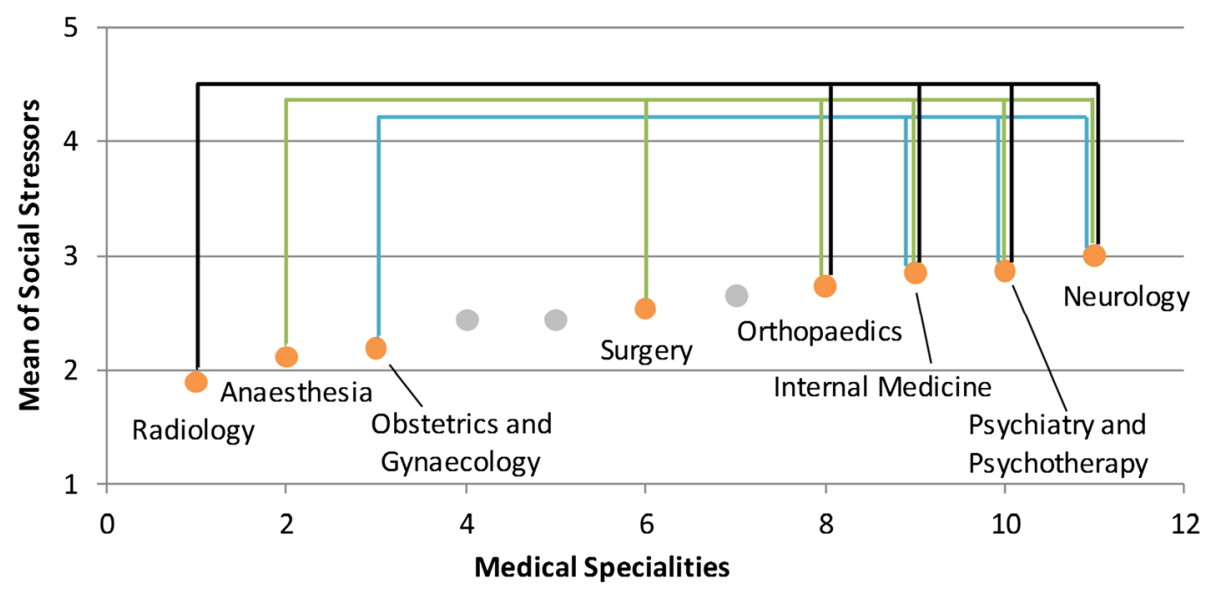

Figure 4 Differences between radiology, anaesthesia, or gynaecology and other specialities in social stressors with patients/families. This is only a schematic figure of the differences found in social stressors with patients/families. For detailed results use Table 2.

with patients and their families were predictable, if the differences in patient contact were considered for the different specialities. Specialities such as neurology, psychiatry and psychotherapy, and internal medicine inherently involve more communication with patients (e.g., for diagnosis) than in radiology or anaesthesia. Regarding uncertainty (e.g., consequences that are difficult to predict) and social stressors with patients, neurologists not only showed significant differences, but gave the highest ratings compared to the other specialities. As these stressors are presumably related to the medical problems in this speciality, it would be useful to investigate the role of resources (both, situation- and person-related) on stressoutcomes.

The results of the multiple regression analyses show that time pressure, frustration about how work needs to be done and emotional dissonance are related to different stress-outcomes. A prior study has already shown that time pressure is associated with a high feeling of stress in physicians [1]. The current results support this feeling perceived by physicians. The frustration about how work needs to be done means restrictions due to documentation and administration work. At least for surgeons and internal physicians, these tasks take up about

Table 3 Hierarchical multiple regression analyses explaining irritation and emotional exhaustion

\begin{tabular}{|c|c|c|c|c|c|c|}
\hline & \multicolumn{3}{|c|}{ DV: irritation } & \multicolumn{3}{|c|}{ DV: emotional exhaustion } \\
\hline & $r$ & $\beta$ & $\Delta R^{2}$ & $r$ & $\beta$ & $\Delta R^{2}$ \\
\hline Step 1: Control variables & & & $.02^{* *}$ & & & $.05^{* * *}$ \\
\hline Medical speciality & -.03 & $-.07^{*}$ & & .05 & .00 & \\
\hline Professional position & $-.12^{* *}$ & -.02 & & $-.02^{* * *}$ & $-.15^{* * *}$ & \\
\hline Age & $-.13^{* * *}$ & -.04 & & $-.18^{* * *}$ & .01 & \\
\hline Gender & $.11^{* *}$ & $.12^{* * *}$ & & $.10^{* *}$ & $.07^{*}$ & \\
\hline Step 2: Task-related stressors & & & $.21^{* * *}$ & & & $.32^{* * *}$ \\
\hline Time pressure & $.37^{* * *}$ & $.16^{* * *}$ & & $.48^{* * *}$ & $.28^{* * *}$ & \\
\hline Uncertainty & $.36^{* * *}$ & .05 & & $41^{* * *}$ & .02 & \\
\hline Frustration about how work needs to be done & $.40^{* * *}$ & $.12^{* * *}$ & & $.52^{* * *}$ & $.19^{* * *}$ & \\
\hline Step 3: Interaction-related stressors & & & $.07^{* * *}$ & & & $.05^{* * *}$ \\
\hline Problems in workflow due to supervisors and colleagues & $.27^{* * *}$ & .08 & & $.28^{* * *}$ & .02 & \\
\hline Problems in workflow due to other professional groups & $.28^{* * *}$ & .03 & & $.35^{* * *}$ & $.11^{* *}$ & \\
\hline Social stressors with patients/families & $.31^{* * *}$ & .04 & & $.36^{* * *}$ & .03 & \\
\hline Emotional dissonance & $.44^{* * *}$ & $.26^{* * *}$ & & $.45^{* * *}$ & $.19^{* * *}$ & \\
\hline
\end{tabular}

$\mathrm{DV}=$ dependent variable; $r=$ Pearson correlation coefficient; $\beta=$ standardised regression coefficient; $\Delta R^{2}=$ changes in coefficient of determination $R^{2}$ to estimate source of variance. Numerical coding for control variables: medical speciality: $1=$ Anaesthesia (sorted alphabetically) to $11=$ Urology; Professional position: $1=$ assistant physician (sorted in rising order), up to $4=$ chief physician; gender: $1=$ male, $2=$ female

${ }^{*} \mathrm{p}<.05 ;{ }^{* *} \mathrm{p}<.01 ;{ }^{* * *} \mathrm{p}<.001$. 
one third of daily working hours [5]. This illustrates once again how important the relationship between frustration and stress-outcomes is. Thus, it seems to be useful to reduce high levels of frustration.

\section{Strengths and limitations}

As the sample was relatively large, it was possible to compare eleven different specialities. However, a selection bias cannot be excluded. For example, it is possible that unusually stressed physicians took part in this survey. Despite that, the current sample corresponds to the physician statistics of the German Medical Association [21] and the German Federal Bureau of Statistics [22], with respect to age, gender and medical specialities. Another advantage of this study is that it considers two potential stress-outcomes. Nevertheless, the relationships between stressors and health aspects should be interpreted with caution. Because of the cross-sectional design, no causal interpretations are possible. Hints for causal conclusions can only be drawn from longitudinal studies or studies with experimental designs [25]. Moreover, it should be emphasised that several situation-related stressors were considered in the current study, which represent a large part of the hospital physician's everyday work. Although the current analyses focused only on stressors, a further emphasis on resources should be considered because work-related resources are found to be relevant to health as well [26], as mentioned in the transactional stress model of work and organizational psychology.

\section{Practical implications}

Various approaches will be discussed to reduce the stressors of hospital physicians during their daily work. One way to handle social stressors with patients and their families can be found in reflecting these situations. Corresponding to Wilson [27], this could be realised by journaling, critical incident analysis, mentoring, and/or supervision. To reduce the frustration about how work needs to be done, it may be advantageous to introduce personalised training of key qualifications for handling administrative work. At the organisational level, it would be useful to improve staff planning and to reduce documentation and administrative work. One alternative could be to examine ways to facilitate the documentation and administrative tasks (e.g., easily manageable technical tools or more autonomy) and then to implement these. By reducing frustration about how work needs to be done, one could also reduce time pressure, as these two characteristics are closely correlated $(r=.51, p<.001)$. The positive relationship between emotional dissonance (the suppression or control of the emotions) and emotional exhaustion has already been demonstrated for other professions, and high autonomy was shown to compensate the effects of high emotional dissonance [28]. For emotional exhaustion, problems in workflow due to other professional groups seem to be a relevant predictor. In order to reduce these problems, it seems to be useful to clarify the causes. There might be organisational reasons that agreements cannot be kept. But difficulties might also be caused by social conflicts, which have been found to be a frequent problem for assistant physicians [1]. In order to identify causes, interdisciplinary and cross-hierarchical working groups could be an adequate method [29] (e.g., focused on workflows and communication issues).

\section{Conclusions}

The results of the current study demonstrated that hospital physicians experience certain work stressors differently with respect to their medical speciality. Therefore, stress prevention programs should consider these differences. Additionally, the meaning of time pressure, frustration about how work needs to be done, and emotional dissonance for aspects of health was illustrated. Aside longitudinal studies are needed in order to verify these crosssectional findings; these results suggest some approaches for health promoting improvements.

\section{Competing interests}

The authors declare that they have no competing interests.

\section{Authors' contributions}

GT made substantial contributions to conception and design of the study, to the acquisition of data, and to the analysis and interpretation of data; she was involved in drafting the manuscript as well as revising it critically. EB made substantial contributions to conception and design of the study; she was involved in drafting the manuscript as well as revising it critically. AK was involved in the acquisition of data, in the interpretation of the data, and in drafting the manuscript as well as revising it critically. MK was involved in conception and design of the study, in the acquisition of data, and in drafting the manuscript as well as revising it critically. AN was involved in conception and design of the study, and in drafting the manuscript as well as revising it critically. All authors read and approved the final manuscript.

\section{Acknowledgements}

This study was financed by the Institution for Statutory Accident Insurance and Prevention in the Health and Welfare Services.

\section{Author details}

${ }^{1}$ University of Hamburg, Work and Organisational Psychology, Von-Melle-Park 11, 20146 Hamburg, Germany. ${ }^{2}$ University Medical Center

Hamburg-Eppendorf, Institute for Health Services Research in Dermatology and Nursing (IVDP), Martinistraße 52, 20246 Hamburg, Germany. ${ }^{3}$ Institute for Statutory Accident Insurance and Prevention in the Health and Welfare Services (BGW), Principles of Prevention and Rehabilitation Department (GPR), Pappelallee 33/35/37, 22089 Hamburg, Germany.

Received: 28 October 2014 Accepted: 18 February 2015

Published online: 25 February 2015

\section{References}

1. Cohen JS, Patten S. Well-being in residency training: a survey examining resident physician satisfaction both within and outside of residency training and mental health in Alberta. BMC Med Educ. 2005;5:21-31.

2. Fuß I, Nübling M, Hasselhorn H-M, Schwappach D, Rieger MA. Working conditions and work-family conflict in German hospital physicians: psychosocial and organisational predictors and consequences. BMC Public Health. 2008;8:353-69. 
3. Glaser J, Höge T. Spezifische Anforderungen und Belastungen personenbezogener Krankenhausarbeit. In: Badura B, Schellschmidt H, Vetter C, editors. Fehlzeitenreport 2004 Gesundheitsmanagement Krankenhäusern und Pflegeeinrichtungen. Berlin: Springer; 2004. p. 51-64.

4. Weigl M, Müller A, Vincent C, Angerer P, Sevdalis N. The association of workflow interruptions and hospital doctors' workload: a prospective observational study. BMJ Qual Saf. 2012;21:399-407.

5. Weigl M, Müller A, Zupanc A, Angerer P. Participant observation of time allocation, direct patient contact and simultaneous activities in hospital physicians. BMC Health Serv Res. 2009;9:110-21.

6. Buddeberg-Fischer B, Klaghofer R, Stamm M, Siegrist J, Buddeberg C. Work stress and reduced health in young physicians: prospective evidence from Swiss residents. Int Arch Occup Environ Health. 2008;82:31-8.

7. Unrath M, Zeeb H, Letzel S, Claus M, Escobar Pinzón LC. The mental health of primary care physicians in Rhineland-Palatinate, Germany: the prevalence of problems and identification of possible risk factors. Dtsch Arztebl Int. 2012;109:201-7.

8. Bamberg E, Keller M, Wohlert C, Zeh A. BGW-Stresskonzept. Hamburg: Berufsgenossenschaft für Gesundheitsdienst und Wohlfahrtspflege (BGW); 2006. p. 1-28.

9. Weigl M, Hornung S, Petru R, Glaser J, Angerer P. Depressive symptoms in junior doctors: a follow-up study on work-related determinants. Int Arch Occup Environ Health. 2012;85:559-70.

10. Buddeberg-Fischer B, Klaghofer R, Buddeberg C. Arbeitsstress und gesundheitliches Wohlbefinden junger Ärztinnen und Ärzte. Z Psychosom Med Psychother. 2005;51:163-78.

11. Estryn-Behar M, Doppia M-A, Guetarni K, Fry C, Machet G, Pelloux P, et al. Emergency physicians accumulate more stress factors than other physicians - Results from the French SESMAT study. Emerg Med J. 2011;28:397-410.

12. Prins JT, Hoekstra-Weebers JEHM, Gazendam-Donofrio SM, Dillingh GS, Bakker $A B$, Huisman $M$, et al. Burnout and engagement among resident doctors in the Netherlands: a national study. Med Educ. 2010;44:236-47.

13. Rosta J. Arbeitszeit der Krankenhausärzte in Deutschland. Dtsch Arztebl. 2007;104:2417-24.

14. Keller M, Bamberg E, Kersten M, Nienhaus A. Instrument for stress-related job analysis for hospital physicians: validation of a short version. J Occup Med Toxicol. 2013;8:10-20.

15. Mohr G, Rigotti T, Müller A. Irritation - ein Instrument zur Erfassung psychischer Beanspruchung im Arbeitskontext. Skalen- und Itemparameter aus 15 Studien. Zeitschrift für Arbeits- und Organ. 2005;49:44-8.

16. Enzmann D, Kleiber D. Helfer-Leiden: Streß Und Burnout in Psychosozialen Berufen. Heidelberg: Asanger; 1989.

17. Maslach C, Schaufeli WB, Leiter MP. Job burnout. Annu Rev Psychol. 2001;52:397-422.

18. Siegrist J. Adverse health effects of high-effort/low-reward conditions. J Occup Health Psychol. 1996;1:27-41.

19. Heinke W, Dunkel P, Brähler E, Nübling M, Riedel-Heller S, Kaisers UX Burn-out in der Anästhesie und Intensivmedizin. Der Anästhesist. 2011;12:1109-18.

20. Victor A, Elsäßer A, Hommel G, Blettner M. Judging a plethora of p-values. Dtsch Arztebl Int. 2010;107:50-6.

21. Ärztestatistik 2012. [http://www.bundesaerztekammer.de/page.asp? his $=0.3 .11372]$.

22. Statistisches Bundesamt - Tabellen: Beschäftigte im Gesundheitswesen (Code 23621) [https://www-genesis.destatis.de/genesis/online/data].

23. Jenaro C, Flores N, Orgaz MB, Cruz M. Vigour and dedication in nursing professionals: towards a better understanding of work engagement. J Adv Nurs. 2011:67:865-75.

24. Sonnentag S, Mojza EJ, Demerouti E, Bakker AB. Reciprocal relations between recovery and work engagement: the moderating role of job stressors. J Appl Psychol. 2012;97:842-53.

25. Angerer P, Petru R, Nowak D, Weigl M. Arbeitsbedingungen und Depression bei Ärzten. Dtsch Medizinische Wochenschrift. 2008;133:26-9.

26. Richter A, Kostova P, Harth V, Wegner R. Children, care, career - a crosssectional study on the risk of burnout among German hospital physicians at different career stages. J Occup Med Toxicol. 2014;9:1-9.
27. Wilson H. Reflecting on the "difficult" patient. N Z Med J. 2005;118:1-6.

28. Grandey AA, Fisk GM, Steiner DD. Must "service with a smile" be stressful? The moderating role of personal control for American and French employees. J Appl Psychol. 2005;90:893-904.

29. Münch E. Health promotion in hospitals - evaluation of health circles as a means of health promotion in workplaces and organization. J Public Health. 1996;4:318-34

\section{Submit your next manuscript to BioMed Central and take full advantage of:}

- Convenient online submission

- Thorough peer review

- No space constraints or color figure charges

- Immediate publication on acceptance

- Inclusion in PubMed, CAS, Scopus and Google Scholar

- Research which is freely available for redistribution 